\title{
Evaluation of anti-fatigue property of the extruded product of cereal grains mixed with Cordyceps militaris on mice
}

\author{
Lei Zhong ${ }^{1}$, Liyan Zhao ${ }^{1}$, Fangmei Yang ${ }^{1}$, Wenjian Yang ${ }^{2}$, Yong Sun ${ }^{3}$ and Qiuhui Hu ${ }^{1 *}$
}

\begin{abstract}
Background: Fatigue is a biological phenomenon that involves a feeling of extreme physical or mental tiredness that could potentially cause some severe chronic diseases. Recently, diet therapy has provided a new alternative to alleviate physical fatigue. In our previous study, addition of Cordyceps militaris (C. militaris) into an extruded product was shown to provide high nutrition and unique flavors; however, little is known whether this product has some scientific evidence regarding anti-fatigue property. The purpose of this study was to evaluate the anti-fatigue effects of extruded products of cereal grains (EC) and EC mixed with C. militaris (ECC).
\end{abstract}

Methods: The mice were divided into seven groups: one group received distilled water (Control group, $n=20$ ), and the other groups received different dosages of EC $(5,10$ and $20 \mathrm{~g} / \mathrm{kg}$ body weight, $n=20$ per group) or of ECC $(5,10$ and $20 \mathrm{~g} / \mathrm{kg}$ body weight, $n=20$ per group) solution in water. All of the mice were administered with distilled water, EC or ECC continuously for 30 days by gavage and the anti-fatigue activity was evaluated using a weight-loaded swimming test, along with assessments of fatigue-related indicators. The mode of fighting fatigue was investigated by determining changes in exercise endurance and biochemical markers, including exhaustive swimming time, lactate dehydrogenase (LDH), blood lactic acid (BLA), creatine kinase (CK), blood urea nitrogen (BUN), malondialdehyde (MDA), glutathione peroxidase (GSH-PX), superoxide dismutase (SOD), catalase (CAT), and hepatic and muscle glycogen levels.

Results: EC and ECC prolonged the swimming endurance time of mice compared to the control. The content of BLA at high dose of ECC group $(20 \mathrm{~g} / \mathrm{kg}$ ) was significantly lower than that in the negative control group. CK, BUN and MDA levels were significantly reduced by treatment with EC and ECC compared to the negative control, while the low and middle dose of EC had no significant effect on MDA levels. Additionally, only the middle and high dose of EC (10, $20 \mathrm{~g} / \mathrm{kg})$ could significantly decrease the BUN level. EC and ECC treatments increased glycogen, LDH, SOD, CAT and GSH-Px levels. Low and middle dose of EC had no significant effects on muscle glycogen. Moreover, low dose of EC could increase the level of SOD but it was not statistically significant. Compared to the EC treatment groups, ECC demonstrated the efficacy of anti-fatigue potential, particularly at a high dose of ECC, the best performance in relieving fatigue.

Conclusions: These results suggest that EC and ECC could prevent exercise-induced fatigue in mice and ECC provided a better effect. In addition, C. militaris in ECC might play a crucial role in the anti-fatigue activity of ECC.

Keywords: Anti-fatigue, Extruded product, Cereal grains, Cordyceps militaris

\footnotetext{
* Correspondence: qiuhuihu@njau.edu.cn

${ }^{1}$ College of Food Science and Technology, Nanjing Agricultural University,

Nanjing 210095, China

Full list of author information is available at the end of the article
} 


\section{Background}

Physical fatigue is commonly defined as an inability to sustain or maintain voluntary activities, which is considered to be associated with the decline of physiology $[1,2]$. Regular exercise, a balanced diet, and complementary and alternative medicine (CAM) are reported to effectively relieve fatigue, including providing energy substrates and enhancing elimination of metabolites. Among these approaches, CAM dietary therapy has been widely used in medical treatment and health care due to its minor side effects $[3,4]$.

Whole cereal grains as healthy foods have gained popularity due to their underlying protection against diet-related disorders, such as fatigue, obesity, diabetes and even cancers [5-8]. In addition, the limited amino acids of cereal and legume were lysine and methionine respectively, while mixed cereal grains are able to compensate for deficiencies in the content and constitution of essential amino acids from a single source. Currently, mixed cereal grains have been applied to design and produce nutritional foods that are rich in dietary fiber and protein [9].

In recent years, research on extruded products including edible mushrooms has received increased attention in order to obtain an improved nutritional value, texture, flavor and digestion of food under conditions of thermal force and ultra-high pressure [10-13]. C. militaris is a fungus renowned for its health-promoting properties, as well as for its medicinal use in Southeast Asia [14]. In a previous study, $C$. militaris was demonstrated to be a high quality protein and rich amino acid, which contains $29.43 \%$ protein, $2.51 \%$ fat, $1.20 \%$ dietary fiber, $37.52 \%$ carbohydrate and $0.051 \%$ cordycepin etc. Moreover, its bioactive components such as cordycepin, polysaccharides, ergosterol, and adenosine, play a key role in health care, and are used for various medicinal purposes such as anti-aging, anti-tumor, anti-cancer and anti-leukemic etc. [15-17]. C. militaris was also often used in the formulation of functional foods. Inclusion of $C$. militaris into chicken essence products could be nutritional and healthy for consumers [18]. Recently, the aqueous extract of $C$. militaris had been demonstrated to possess the significant effect on resisting oxidation and relieving fatigue in mouse model [19]. Cordyceps sinensis (C. sinensis), widely accepted as tonic and healthy foods in Asia, has received more interests due to its biological activity. Many studies reported that $C$. sinensis has the prominent impacts on analgesic, antitumor, free radical scavenging, and immune modulation [20]. Compared with C. sinensis, the contents of cordycepin, adenine, guanosine and uracil were even higher in C.militaris, while cordycepic acid, amino acid, polysaccharides and inorganic elements levels were lower. Natural C. sinensis is expensive and rare in nature. $C$. militaris has medicinal properties similar to those of $C$. sinensis and could potentially be the alternatives for $C$. sinensis in health supplements. Due to high cost in the development of pharmaceutical drugs, more and more research interests have been put on natural products, which are proved to be safer and more efficacious with less side effects on body. Thus, C. militaris could be used as a high-quality raw material of functional food [21].

Weight-loaded swimming test is the most widely used method to evaluate anti-fatigue properties of compounds through assessing the reduction of muscular force or the exhaustion of contractile function [22]. On the basis of the test, the resistant fatigue mechanisms of compounds could be investigated through a series of biochemical parameters. Several theories have been proposed to explain sports fatigue, including the "exhaustion theory [23]", "radical theory [24]", "clogging theory", "homeo-stasis disturbance theory", "mutation theory" and "protective inhibition theory [25]". Among these theories, the "exhaustion theory", "clogging theory" and "radical theory" have drawn particular attention, which could explain the anti-fatigue effect of the extruded products by evaluating the values of biochemical criteria. The "exhaustion theory" proposed that depletion of muscle and liver glycogen could lead to the ocurrence of fatigue. However, "clogging theory", the excessive accumulation of BLA and BUN would cause metabolic disorders, which eventually result in fatigue. "Radical theory" shows that intense exercise could produce an imbalance between the body's oxidation system and its anti-oxidation system. Muscle cells have the defense mechanisms to scavenge reactive oxygen species, such as SOD, GSH-Px and CAT, and to protect cells against exercise-induced oxidative injury. Currently, research on healthy foods, such as $C$. militaris, Panax quinquefolium and fermented rice bran, have achieved great progress in relieving fatigue by reducing the $\mathrm{CK}$ and BLA contents and increasing glycogen and GSH-Px concentrations [4, 26, 27]. In our previous study, the proportions of cereal grains in a mixed powder were optimized by linear programming. Moreover, ECC was previously shown to possess profound characteristic features, such as the improvement in texture, nutrition and flavors. However, the physiological effects or health functions of ECC remain unclear.

In the previous study, $C$. militaris and blended powders from five cereal grains were prepared; a twin screw extruder was used to produce the extruded products. We hypothesized that EC and ECC could alleviate fatigue in mice and adding $C$. militaris could enhance the antifatigue effect of EC. To test the hypothesis, we established the mouse model of sports fatigue and studied the changes in anti-fatigue and anti-oxidant activities of EC and ECC. The swimming endurance time was determined as an indicator of athletic capability in mice, which could 
intuitively reflect the ability of resistance to fatigue. Following swimming test, mice were subject to a series of biochemical analysis in order to further explore the antifatigue mechanisms of EC and ECC such as measuring $\mathrm{LDH}$ and $\mathrm{CK}$ as well as the levels of BUN, BLA, MDA, muscle and liver glycogen. In addition, the anti-oxidant enzymes including SOD, CAT and GSH-Px were also measured.

\section{Methods}

\section{Plant materials and reagents}

Rice, adlay, red beans, glutinous rice and soybeans were purchased from a local supermarket. C. militaris was provided from Yan Cheng, Jiangsu Province, China.

A liver/muscle glycogen assay kit, urea assay kit, lactate dehydrogenase assay kit, GSH-Px assay kit, MDA assay kit, lactic acid assay kit, SOD assay kit, CAT assay kit and CK assay kit were obtained from Nanjing Jiancheng Bioengineering Institute, Jiangsu Province, China.

\section{Preparation of extruded products}

In our previous study, the composition of the blended cereal grains was calculated using linear programming in Microsoft Excel: 60\% rice, 5\% adlay, 10\% red beans, 10\% glutinous rice and $15 \%$ soybeans. The grains were mixed with C. militaris at a ratio of 10:1 (grains:C. militaris) on a dry-to-dry weight basis. The moisture content of the mixed samples was adjusted to $16 \%$ by spraying the samples with calculated amounts of water, and the samples were then stored at $4{ }^{\circ} \mathrm{C}$ overnight. The extrusion temperature $\left(80{ }^{\circ} \mathrm{C}-90{ }^{\circ} \mathrm{C}-120{ }^{\circ} \mathrm{C}-140{ }^{\circ} \mathrm{C}-165{ }^{\circ} \mathrm{C}\right)$, screw speed $(180 \mathrm{rpm})$ and feed rate $(15 \mathrm{rpm})$ were set by twin screw extrusion (DSE-29/40D, Brabender Co. Ltd., Germany). Wet materials were processed in the barrel into extruded products, and packed under vacuum.

\section{Animals and experimental design}

Approval for the experimental protocol from institutional animal ethical committee was obtained before initiation of the study from Nanjing Agricultural. The study was conducted in the laboratory of the animal center of Nanjing Agricultural University (Nanjing, China) and all of the mice were euthanized at the end of experiment. C57BL/6 male mice weighing approximately $18-22 \mathrm{~g}$ (seven weeks old, specific pathogen-free grade, SPF) were housed under controlled conditions, including the room temperature $\left(25^{\circ} \mathrm{C}\right)$, relative humidity $(50 \%)$, and air flow conditions, with a fixed 12-h light-dark cycle during the experiment. All the mice were allowed free access to water and a standard diet.

The mice were randomly divided into seven groups, with 20 mice in each group. Mice administered with distilled water $(20 \mathrm{~g} / \mathrm{kg}$ body weight) by gavage served as the negative control group (NCG). The treatment mice were fed with EC or ECC by a feeding atraumatic needle once per day for 30 days at a low-dose $5 \mathrm{~g} / \mathrm{kg}$ (EC-L and ECC-L), medium dose of $10 \mathrm{~g} / \mathrm{kg}$ (EC-M and ECC-M) and a high dose of $20 \mathrm{~g} / \mathrm{kg}$ (EC-H and ECC-H). All the mice were fed normal laboratory food and they drank water freely. The high dose was calculated at $20 \mathrm{~g} / \mathrm{kg}$ body weight based on $150 \mathrm{~g}$ cereal grains intake by the adult (60 kg of body weight), and the low- and middledose values were $5 \mathrm{~g} / \mathrm{kg}$ and $10 \mathrm{~g} / \mathrm{kg}$, respectively. All the extruded products were prepared by dissolving in the same volume of distilled water.

\section{Weight-loaded swimming test}

The weight-loaded swimming test was carried out with some modifications [28-30]. Following the last treatment with EC, ECC or distilled water, ten mice in each group rested for $30 \mathrm{~min}$ and were placed in the swimming pool $\left(100 \mathrm{~cm} \times 50 \mathrm{~cm} \times 40 \mathrm{~cm}, 25 \pm 1.5{ }^{\circ} \mathrm{C}\right)$, where the mice were attached to a brass ring of $5 \%$ bodyweight and could only support themselves by touching the bottom with their feet. Exhaustion was determined by the time on observing their loss of coordinated movements and failure to swim. Endurance time was recorded by the experimenters until the mice were completely exhausted and failed to return to surface to breathe within 10s. The exhausted mice were removed from the pool, dried with gauze and returned to their cages.

\section{Sample collection}

The rest of the ten mice were taken out of each group to swim for the determination of organ index and analyses of glycogen and blood biochemical parameters. After the final treatment, they were forced to swim to exhaustion without loads for $90 \mathrm{~min}$ in the same pool and then rested for an hour. The mice subjected to forced swimming test without loads for $90 \mathrm{~min}$ in the same pool and then rested for an hour. These mice were anesthetized with pentobarbital sodium to collect blood, organ and tissue. Blood samples were collected through their eyeballs into heparinized tubes and tubes without anticoagulant. Serum samples were prepared by centrifugation at $1000 \times \mathrm{g}, 4{ }^{\circ} \mathrm{C}$ for $15 \mathrm{~min}$ and were then tested to determine the concentrations of $\mathrm{LDH}, \mathrm{CK}, \mathrm{BUN}$, MDA, GSH-Px, SOD and CAT. Blood plasma was prepared by centrifugation at $1000 \times \mathrm{g}, 4{ }^{\circ} \mathrm{C}$ for $10 \mathrm{~min}$, and then tested to measure the BLA content. Blood analysis was tested in accordance with the instructions for each kit. Liver, brain and leg muscles were quickly dissected. All the organs and tissues were washed in ice-saline and then dried with filter paper for the determination of the organ index. Livers and leg muscles were tested to evaluate the changes in glycogen levels. All the samples were frozen in liquid nitrogen and kept at $-80{ }^{\circ} \mathrm{C}$ until the 
determination was performed. The experiment scheme was shown in Fig. 1.

\section{Determination of the organ index}

Livers, brains and hearts were weighed using electronic scales. The formula of the organ index is shown below:

$$
I=\frac{100 * g}{G}
$$

where $I$ is the organ index, $g$ is the weight of the organ, and $G$ is the weight of the mouse.

\section{Statistical analysis}

Means \pm SD $(n=10)$ are shown in Tables 1 and 2, and the error bars are marked in the figures. One-way analysis of variance (ANOVA) was used to detect statistical significance followed by post hoc multiple comparisons using SPSS 22.0 software (IBM corporation, USA). $P<0.05$ was considered statistically significant.

\section{Results}

\section{Effects of EC and ECC on body weights and on the organ} index

Mice weight were recorded following each treatment during the experiment (Table 1). No significant difference were observed in the initial body weights among the groups $(P>0.05)$. However, mice in the treatment groups appear to be higher than those in the NCG, but the difference was not significant $(P>0.05)$. In addition, there were no significant changes in the organ index for all the mice among the groups $(P>0.05)$.

\section{Effects of EC and ECC on exhaustive swimming capacity}

The exhaustive swimming capacities are shown in Fig. 2. For EC- and ECC-supplemented groups, the exhaustive swimming time was longer than that for the NCG $(P<0.05)$ and increased with a rising concentrations of EC and ECC. In addition, compared to the $\mathrm{EC}-\mathrm{H}$ group, the exhaustive swimming time in the ECC-H group ( $20 \mathrm{~g} / \mathrm{kg}$ body weight) was prolonged by $18.21 \%$, which showed that ECC-H mice had the most significant effect on increasing exhaustive swimming ability.

\section{Effects of EC and ECC on glycogen levels}

Table 2 shows that glycogen levels (muscle and liver glycogen) in the EC- and ECC-supplemented groups were significantly higher than those in the NCG $(P<0.05)$. At the same dose, the mice receiving ECC had significantly higher glycogen levels than those in the EC-supplemented groups $(P<0.05)$. Compared to $\mathrm{EC}-\mathrm{H}$ group, the muscle glycogen levels in the ECC-L, ECC-M and ECC-H groups were increased by $55.11 \%, 73.72 \%$, and $94.53 \%$, and the liver glycogen levels also had an increase of $56.71 \%$, $166.52 \%$ and $225.19 \%$, respectively.

Effects of EC and ECC on the serum LDH and CK activities As shown in Figs. 1, 2, and 3, following swimming test, LDH activity in the ECC-supplemented groups increased significantly compared to that in the NCG. Under the same dosage, the LDH levels in the ECC-supplemented groups were higher than those in the EC-supplemented groups $(P<0.05)$. Compared to EC-H group, LDH contents of mice in the ECC-L, ECC-M and ECC-H groups increased by $1.57 \%, 2.18 \%$ and $3.50 \%$, respectively. In addition, there was no significant dose-dependent fatigue relief in the EC-supplemented groups.

CK activity was determined in order to evaluate the effects of EC and ECC on anti-fatigue capacity (Figs. 1, 2, and 3). Compared with the NCG, significant decreases $(P<0.05)$ in the CK level were observed in the EC- and ECC-supplemented groups. Under the same dosage, CK activities in the ECC-supplemented groups were significantly $(P<0.05)$ lower than those in the EC-supplemented groups. Compared with the EC-H group, the CK concentration in mice in the ECC-L, ECC-M and ECC-H group decreased by $0.51 \%, 2.72 \%$ and $5.18 \%$ respectively, indicating that ECC-H resulted in the most significant reduction in the CK level.

\section{Effects of EC and ECC on BLA and BUN levels and on MDA activity}

Compared with the NCG, the BLA concentration in the ECC- $\mathrm{H}$ treatment groups showed a significant reduction, as shown in Figs. 2 and 3. The mice in the ECC-M and ECC-H groups had lower $(P<0.05)$ BLA levels than those in the EC-supplemented groups. Compared with

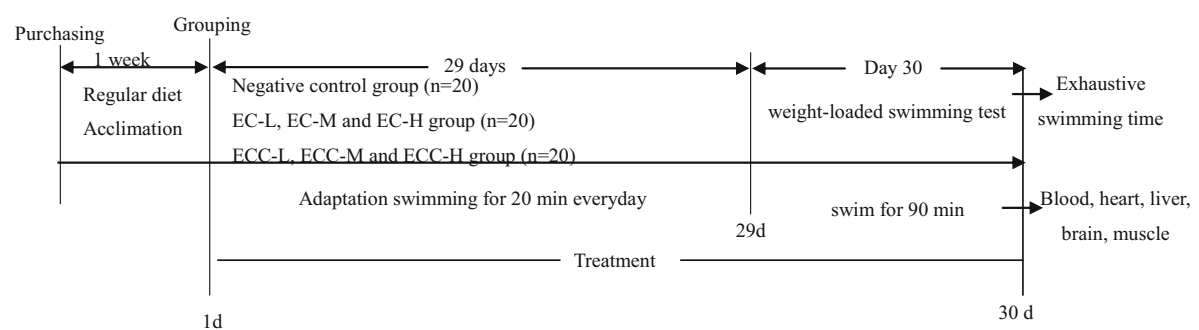

Fig. 1 Experiment scheme 
Table 1 Effects of EC and ECC on body weight changes and organ index in mice

\begin{tabular}{|c|c|c|c|c|c|c|c|}
\hline \multirow[t]{2}{*}{ Group } & \multicolumn{4}{|l|}{ Body weight (g) } & \multicolumn{3}{|l|}{ Organ index } \\
\hline & Initial & Seventh day & Intermediate & Final & Liver & Brain & Heart \\
\hline NCG & $18.894 \pm 0.845$ & $19.604 \pm 0.462$ & $21.592 \pm 0.504$ & $23.097 \pm 0.592$ & $0.030 \pm 0.020$ & $0.055 \pm 0.066$ & $0.009 \pm 0.005$ \\
\hline EC-L & $19.159 \pm 0.445$ & $20.436 \pm 0.773$ & $22.077 \pm 0.913$ & $23.082 \pm 1.128$ & $0.023 \pm 0.008$ & $0.047 \pm 0.066$ & $0.015 \pm 0.038$ \\
\hline EC-M & $19.274 \pm 1.327$ & $20.135 \pm 1.304$ & $21.954 \pm 1.166$ & $23.392 \pm 0.960$ & $0.022 \pm 0.007$ & $0.050 \pm 0.024$ & $0.013 \pm 0.041$ \\
\hline $\mathrm{EC}-\mathrm{H}$ & $19.725 \pm 0.736$ & $20.783 \pm 1.141$ & $22.583 \pm 1.386$ & $23.537 \pm 1.568$ & $0.021 \pm 0.018$ & $0.046 \pm 0.002$ & $0.012 \pm 0.008$ \\
\hline ECC-L & $19.774 \pm 0.793$ & $20.647 \pm 0.898$ & $22.581 \pm 0.956$ & $23.223 \pm 1.081$ & $0.025 \pm 0.011$ & $0.048 \pm 0.082$ & $0.016 \pm 0.079$ \\
\hline ECC-M & $19.462 \pm 0.833$ & $20.220 \pm 0.864$ & $22.149 \pm 0.948$ & $22.993 \pm 1.364$ & $0.024 \pm 0.010$ & $0.049 \pm 0.019$ & $0.011 \pm 0.115$ \\
\hline $\mathrm{ECC}-\mathrm{H}$ & $19.528 \pm 1.087$ & $20.687 \pm 1.118$ & $22.356 \pm 1.525$ & $23.468 \pm 1.504$ & $0.027 \pm 0.005$ & $0.051 \pm 0.060$ & $0.014 \pm 0.098$ \\
\hline
\end{tabular}

Treatment with distilled water $(20 \mathrm{~g} / \mathrm{kg})$, EC and ECC $(5 \mathrm{~g} / \mathrm{kg}, 10 \mathrm{~g} / \mathrm{kg}, 20 \mathrm{~g} / \mathrm{kg})$ for 30 days; the body weight was recorded before experiment (initial), the seventh day, after 14 days (intermediate) and after 28 days (final); after exhaustive swimming, the liver, brain and heart index were detected. Values are means \pm standard deviations

the EC-H group, the BLA levels in the ECC-L, ECC-M and ECC-H groups evidently decreased $(P<0.05)$ by $1.23 \%, 5.38 \%$ and $9.06 \%$, respectively.

BUN is a sensitive indicator of exercise capacity (Figs. 2 and 3). Compared to the NCG, the BUN levels in the EC-M, EC-H group and ECC-supplemented groups were significantly $(P<0.05)$ reduced. The BUN levels in the ECC-supplemented groups were lower than those in the EC-supplemented groups. Additionally, compared to the EC-H group, the BUN level in the ECC-L, ECC-M and ECC- $\mathrm{H}$ group significantly decreased by $2.05 \%, 12.45 \%$ and $14.29 \%$, respectively.

As shown in Fig. 4, the serum MDA levels in the EC$\mathrm{H}$ and ECC treatment groups were significantly lower $(P<0.05)$ than those in the NCG. Compared with the EC$\mathrm{H}$ group, the serum MDA levels of the mice in the ECCL, ECC-M and ECC-H groups decreased by $3.90 \%, 8.05 \%$ and $8.83 \%$, respectively. Additionally, the data showed that EC-H and ECC treatment groups showed similar reductions in the MDA level after exhaustive swimming, while it did not achieve statistical significance.

Table 2 Effects of EC and ECC on glycogen levels from muscle and liver

\begin{tabular}{lcc}
\hline Group & $\begin{array}{l}\text { Muscle glycogen } \\
\text { (mg/g muscle) }\end{array}$ & $\begin{array}{l}\text { Liver glycogen } \\
\text { (mg/g liver) }\end{array}$ \\
\hline NCG & $0.093 \pm 0.009$ & $0.081 \pm 0.003$ \\
EC-L & $0.207 \pm 0.078$ & $1.062 \pm 0.083^{*}$ \\
EC-M & $0.213 \pm 0.103$ & $1.244 \pm 0.090^{*}$ \\
EC-H & $0.274 \pm 0.051^{*}$ & $1.326 \pm 0.079^{*}$ \\
ECC-L & $0.425 \pm 0.007^{* a}$ & $2.078 \pm 0.055^{* a}$ \\
ECC-M & $0.476 \pm 0.010^{* b}$ & $3.534 \pm 0.083^{* b}$ \\
ECC-H & $0.533 \pm 0.021^{* \mathrm{c}}$ & $4.312 \pm 0.131^{* \mathrm{c}}$ \\
\hline
\end{tabular}

Treatment with distilled water $(20 \mathrm{~g} / \mathrm{kg})$, EC and ECC $(5 \mathrm{~g} / \mathrm{kg}, 10 \mathrm{~g} / \mathrm{kg}, 20 \mathrm{~g} / \mathrm{kg})$ for 30 days; After exhaustive swimming, the muscle and liver glycogen level were determined. Values are means \pm standard deviations $(n=10)$. $(*) p<0.05$ indicate statistically significant differences versus NCG; (a), (b), (c) $p<0.05$ indicate statistically significant differences versus EC-L, EC-M and EC-H group respectively

\section{Effects of EC and ECC on the activities of antioxidant enzymes}

Except for SOD level in EC-L group, for the EC- and ECC-supplemented groups, CAT, GSH-Px and SOD activities were significantly $(P<0.05)$ higher than those in the NCG (Fig. 5). The mice in the ECC-supplemented groups showed better improvement in CAT, GSH-Px and SOD levels than mice in the EC-supplemented groups. Compared with the EC-L, EC-M and EC-H groups, the SOD levels of mice in the ECC-supplemented groups were increased by $14.17 \%$ (ECC-L), $17.8 \%$ (ECC-M) and $12.65 \%$ $(\mathrm{ECC}-\mathrm{H})$, and CAT activity levels of mice in the ECCsupplemented groups had increases of $40.09 \%$ (ECC-L), $51.59 \%(E C C-M)$ and $58.83 \%$ (ECC-H). Compared with the EC-supplemented groups, the concentration of GSH-

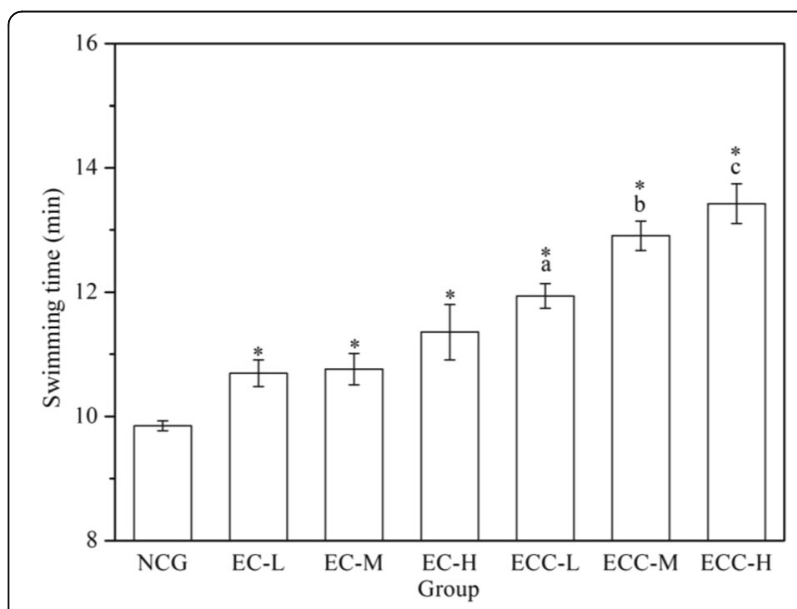

Fig. 2 Effects of EC and ECC on exhaustive swimming time in mice. Male C57BL/6 mice were divided into 7 groups that were given distilled water or different dosages of EC or ECC $(5 \mathrm{~g} / \mathrm{kg}, 10 \mathrm{~g} / \mathrm{kg}$ or $20 \mathrm{~g} / \mathrm{kg}$ ), and the exhaustive swimming test was performed. Values are expressed as the mean \pm SEM. The error bars represent one standard deviation, and $\left({ }^{*}\right) p<0.05$ indicate statistically significant differences versus NCG; (a), (b), (c) $p<0.05$ indicate statistically significant differences versus EC-L, EC-M and EC-H group respectively (the same below) 

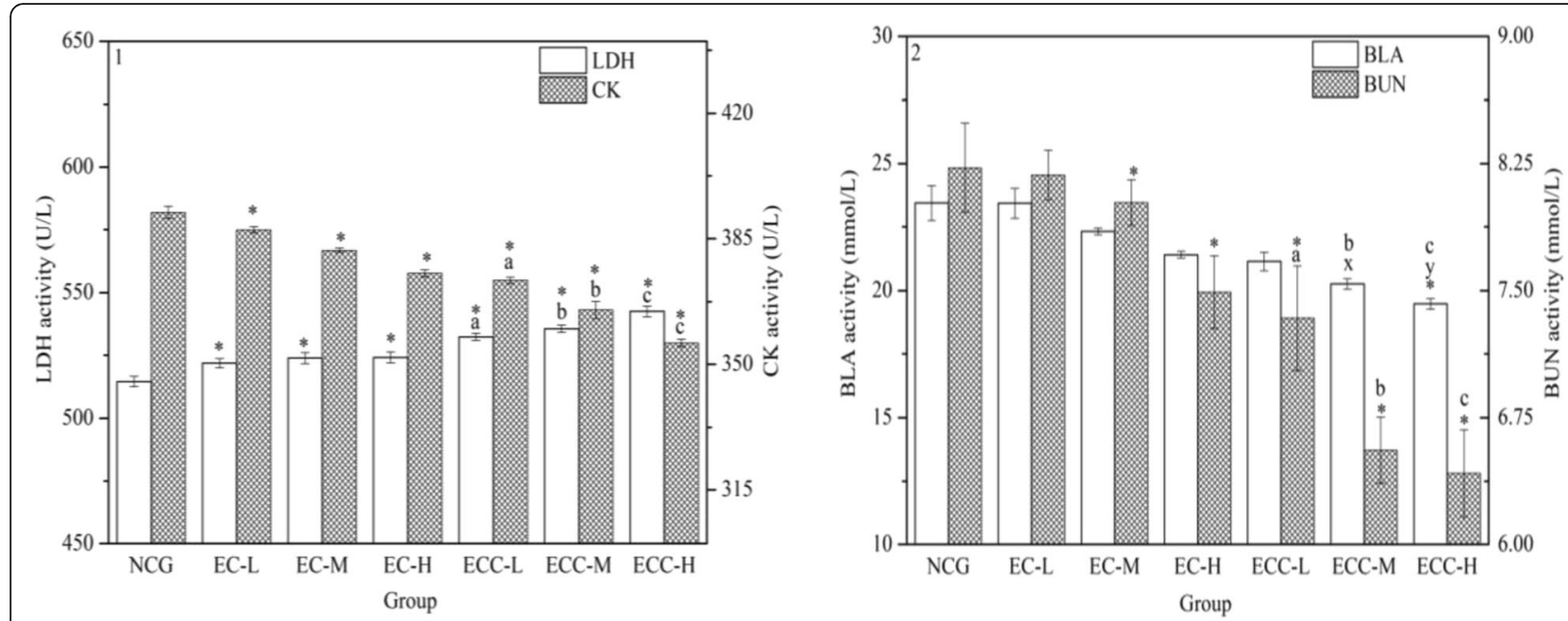

Fig. 3 Effects of EC and ECC on LDH and CK activities (1) and on BLA and BUN levels (2) in mice. Male C57BL/6 mice were treated with EC or ECC $(5 \mathrm{~g} / \mathrm{kg}, 10 \mathrm{~g} / \mathrm{kg}$ or $20 \mathrm{~g} / \mathrm{kg}$ ), and LDH and CK activities (1) and BLA and BUN levels (2) were measured. Values are expressed as the mean \pm SEM. The error bars represent one standard deviation, and $(\mathrm{x}),(\mathrm{y}) p<0.05$ indicate statistically significant differences versus EC-supplemented groups (the same below)

Px in the ECC-supplemented groups showed significant increases $(P<0.05)$ of $11.18 \%(\mathrm{ECC}-\mathrm{L}), 8.7 \%(\mathrm{ECC}-\mathrm{M})$ and $6.12 \%(\mathrm{ECC}-\mathrm{H})$.

\section{Discussion}

The present study was designed to evaluate the effects of EC and ECC on endurance exercise in mice. The major findings are listed below:

The ratio of organ to body by weight was regarded as the organ index, which has been commonly used in toxicity tests. Organ damage could be evaluated in terms of the brain-body index [31]. Additionally, the interactions of boron and calcium were observed in the spleen-body index [32]. In our study, EC and ECC had no obvious

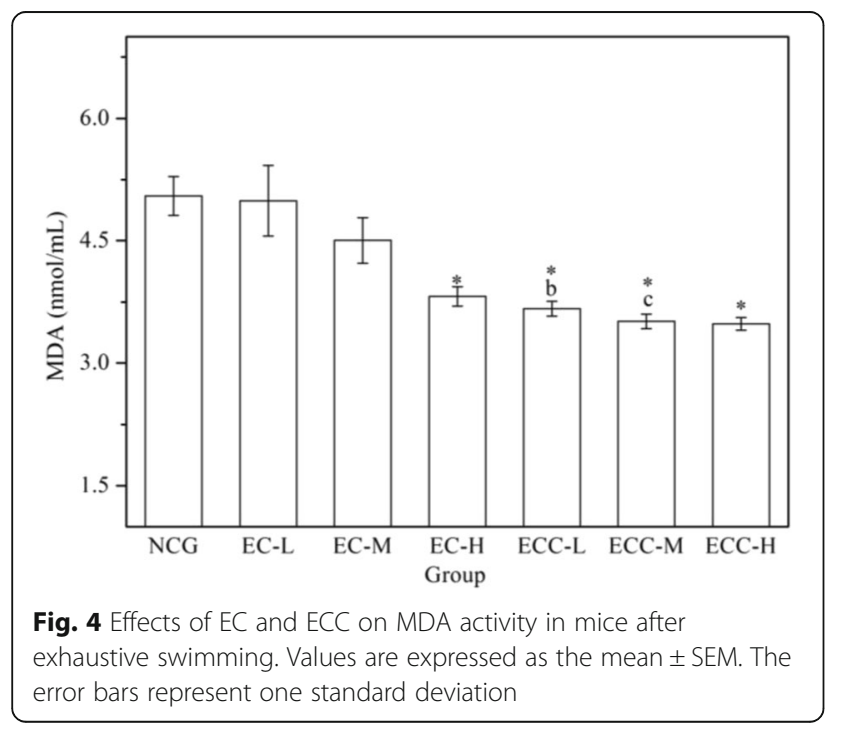

effects on body weights or on the organ index among the groups, suggesting that all mice showed normal growth and that the extruded products had no toxic side effects on the mice during the experiment. In addition, the reason that the lower body weights of mice may be due to the fact that training can be helpful for the digestion of mice.

The fatigue tests including the weight-loaded swimming test, rolling-bar test, pole-climbing test and mouse tail suspension test can be performed to assess athletic ability [33, 34]. Changes of biochemical markers caused by loaded exercise were not completely consistent with sports intensity and not all of markers were suitable for

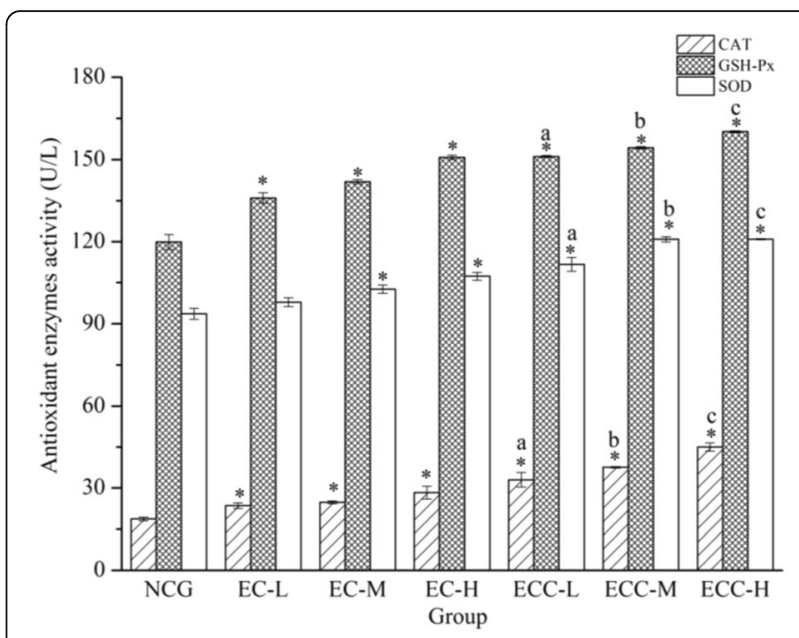

Fig. 5 Effects of EC and ECC on the activities of antioxidant enzymes (CAT, SOD and GSH-Px) in mice after exhaustive swimming. Values are expressed as the mean \pm SEM. The error bars represent one standard deviation 
evaluating the anti-fatigue effect. Among these tests, the anti-fatigue effect of EC and ECC can be evaluated by the weight-loaded swimming test, combining with fatigue related indicators. This method is standard as well as accurate, and it has been adopted widely by most of the researchers and China Food and Drug Administration [4, 30, 35, 36]. However, rolling-bar test, poleclimbing test and mouse tail suspension test require the technical equipment and it is not easy for experimenters to operate them expertly. Lactate test is also often used to evaluate the anti-fatigue effect of compounds on mice after exhaustive exercise, while the test requires the blood sample in inner canthus of each mouse before and after exercise. The procedure may be cumbersome and time consuming to test the lactate level of mice. However, in the weight-loaded swimming test, the workload could be standardized by adding the known amount of load to the tail of the animal to reduce the swimming time, and the endurance time was then recorded accurately, which would be practical to achieve accurate measurements in time [29]. The average of exhaustive swimming time for 4-week-old C57BL/6 mice is $42.2 \mathrm{~min}$ (flow rate is $7 \mathrm{l} / \mathrm{min}$ ) [37]. In our study, after the weight-loaded swimming test, the remaining mice in each group were exhausted in weight-unloaded swimming within 90 min following the standard of exhaustion, which could lessen the effects of stimulation and interference on mice and accord with the generating mechanisms of fatigue. In addition, the concentrations of relevant indicators such as serum CK, BLA, BUN and glycogen, could be raised in exhaustive exercise and it will help improving the quality of detection [38].

For anti-fatigue experiments, the weight-loaded swimming test has been widely used to provide a more informative evaluation of exercise tolerance in animals [39]. Thus, the improvement in exercise endurance will be strong evidence for the anti-fatigue effect [29]. In our study, the results demonstrated that mice in the EC- and ECC-supplemented groups had prolonged swimming time, suggesting that EC/ECC could resist fatigue and ECC supplementation had the most significantly efficient effect, especially at the dose of $20 \mathrm{~g} / \mathrm{kg}$. These evidence collectively suggested that ECC-H group had the greatest $(P<0.05)$ anti-fatigue effect among the groups and $C$. militaris could effectively enhance the stamina of mice and delay the emerging fatigue [40]. Stress response represents the reaction of the body and disturbance of normal physiologic balance, along with physiologic changes including the increase of $\mathrm{LDH}$, glucose, cholesterol levels. Moreover, the glucose level of mice could be increased in response to acute perturbations in the environment and it is helpful to increase exhaustive swimming time [41]. Thus, effects of EC and ECC on the recovery from exhaustion could be related to a resistance to the stress in exhaustive swimming. Most researchers choose Kunming, C57BL/6 and BALB/c mice (6-8 weeks) to establish fatigue model $[4,42,43]$. In our study, all of the mice had been forced to swim for $20 \mathrm{~min}$ after each treatment so as to be accustomed to swimming, Thus, the ages of mice would make a little impact on stress response.

Glycogen was used for long-term energy storage and could be consumed quickly to satisfy the emergent need for glucose when fatigue occurred [44]. Increasing glycogen levels in the liver and muscle could enhance endurance during exhaustive exercise [45]. EC and ECC are rich in proteins and carbohydrates, which could contribute to the storage of glycogen $[42,46]$. Muscle and liver glycogen level increased with the increasing EC and ECC concentrations, which showed that the anti-fatigue activity of EC and ECC might be related to the improvement in the metabolic control of exercise and to the activation of energy metabolism [41]. There is also evidence showing that increasing the availability of fatty acids is mediated by a deceleration of glycogen depletion [43, 47]. C. militaris in ECC may decrease carbohydrate utilization by increasing lipid utilization during exercise, which could delay the rate of glycogen consumption. In addition, during the exhaustive exercise, myocytes will consume continuous anaerobic ATP which can be generated via oxidative phosphorylation in the contractile muscle. Under the above conditions, glycogen will be converted into glucose to generate ATP [48]. The aqueous extracts of $C$. militaris administration could increase ATP levels of mice after exhaustive swimming [19]. In our study, C. militaris in ECC may reduce glycogen consumption by increasing the concentration of ATP which would be helpful for mice to increase endurance in exhaustive swimming.

LDH activity indicates the degree of lactate metabolism, and the anti-fatigue activity could be evaluated by measuring LDH levels [49]. LDH has the ability to quench BLA, which is derived from the anaerobic metabolism of glucose during high-strength exercise $[45,50]$. The data suggested that extruded products, especially $C$. militaris in ECC, could be beneficial to accelerate the metabolism of BLA by effectively strengthening the activity of LDH, which would effectively delay the generation of fatigue [19]. The CK level plays an important role as an indicator of fatigue [38]. An increase in the CK level may be due to damage of the skeletal muscle cell membrane induced by exhaustive exercise [51]. In our study, the results indicated that a high dose of $C$. militaris in ECC could make great contributions to anti-fatigue activity by accelerating the elimination of lactic acid from cells and by efficiently utilizing energy with potential scavenging of free radicals [37].

BLA is the fermented product of carbohydrates without oxygen, and BLA levels increase during anaerobic exercise [26, 41]. In addition, BLA decreases $\mathrm{pH}$ and 
affects the function of cardiac circulation and skeletal muscle systems [52]. The results showed that mice in the ECC-supplemented groups, especially those mice in the ECC-H group, showed a reduction in muscular lactate levels and an increased relative contribution of aerobic metabolism to ATP production during an exercise session [51].

When the body cannot achieve enough energy by metabolizing sugar and fat after a long period of intensive exercise, protein may contribute to the energy supply, and urea nitrogen also increases at this time, which could decrease the strength of the muscle and eventually cause fatigue $[52,53]$. C. militaris extracts showed a significant suppressive effect on BUN, creatinine and urine protein levels in diabetic mice [54]. In our study, mice supplemented with ECC-H $(20 \mathrm{~g} / \mathrm{kg})$ had the lowest BUN concentration, demonstrating that the addition of C. militaris to the EC could relieve fatigue by slowing down the metabolism rate of protein effectively.

Some diseases are relevant to oxidative damage caused by lipid peroxidation, which may produce harmful metabolites [55]. MDA is a product of lipid peroxidation, and its elevation indicates oxidative damage to the cell membrane [56]. Mice that were administered C. militaris polysaccharides at a high dose $(0.2 \mathrm{~g} / \mathrm{kg}$ body weight) had a strong ability to reduce various oxygen free radicals and prevent oxidative stress [53]. In the present study, the rising BUN levels after swimming in the NCG and EC-supplemented group clearly indicated that ECC possessed an ability to lower or retard MDA formation after exercise.

The primary antioxidant enzymes include SOD, CAT and GSH-Px. SOD catalyzes superoxide radicals to produce $\mathrm{H}_{2} \mathrm{O}_{2}$ and $\mathrm{O}_{2}$. CAT and GSH-Px catalyze the breakdown of $\mathrm{H}_{2} \mathrm{O}_{2}$ to form water and $\mathrm{O}_{2}$ [45]. These antioxidant defense mechanisms become weaker during chronic fatigue and other diseases [57]. Hence, an increase in these defense mechanisms can help to recover from fatigue. In our study, the data showed that ECC-H had the most significant effects on promoting increases in the activities of these antioxidant enzymes. At present, C. militaris polysaccharides have been found to protect tissues against oxidative damage in an experiment with mice [53]. Mice in the ECC-supplemented groups possessed a higher capability to prevent lipid oxidation and to preserve cell function by promoting SOD, CAT and GSH-Px levels, indicating that ECC had a better antifatigue effect on mice by improving the function of antioxidation [58].

\section{Conclusions}

In the present study, EC and ECC had prominent antifatigue properties. Our results showed that mice in the ECC-supplemented groups, especially in the ECC-H group $(20 \mathrm{~g} / \mathrm{kg})$, had more significant anti-fatigue effects. It suggested that adding $C$. militaris could enhance the anti-fatigue effect of EC. ECC enhanced the metabolic control of exercise and activated energy metabolism by increasing muscle and hepatic glycogen levels. In addition, C. militaris in ECC may decrease the depletion of glycogen by increasing the availability of fatty acids and ATP level of mice. ECC also efficiently eliminated BLA and protected cells by increasing LDH levels and decreasing CK levels. ECC contributed to the reduction in protein consumption by decreasing BUN levels. Additionally, ECC improved endogenous cellular antioxidant enzymes in ECC-supplemented mice by decreasing MDA levels and increasing CAT, SOD and GSH-Px activities.

In summary, the current study demonstrated that supplementing mice with EC or ECC could promote the capacity for endurance exercise and accelerate recovery from fatigue. ECC had shown the most dramatic antifatigue effect, especially with ECC-H $(20 \mathrm{~g} / \mathrm{kg})$, suggesting that ECC could potentially be included in functional foods for fighting fatigue.

\section{Abbreviations \\ BLA: blood lactic acid; BUN: blood urea nitrogen; C. militaris: Cordyceps militaris; CAM: Complementary and alternative medicine; CAT: Catalase; CK: Creatine kinase; EC: Extruded products of cereal grains; ECC: EC mixed with Cordyceps militaris; ECC-H: High dose of ECC; ECC-L: Low dose of ECC; ECC-M: Middle dose of ECC; EC-H: High dose of EC; EC-L: Low dose of EC; EC-M: Middle dose of EC; GSH-Px: Glutathione peroxidase; LDH: Lactate dehydrogenase; MDA: Malondialdehyde; NCG: Negative control group; SOD: Superoxide dismutase}

\section{Acknowledgments}

We would like to thank all the people who participated in the study and the researchers.

\section{Funding}

Funding assistance for article processing was provided by the China Agriculture Research System (CARS-24) and the Priority Academic Program Development of Jiangsu Higher Education Institutions (PAPD).

\section{Availability of data and materials}

The authors would like to share the data that have been included in the manuscript.

\section{Authors' contributions}

LZ, LZ and WY were responsible for the study design and for data collection and interpretation. LZ, FY, YS and QH performed the statistical analysis. LZ drafted the manuscript. All authors read and approved the final manuscript.

\section{Competing interests}

All the authors declare that they have no competing interests.

Consent for publication

Not applicable.

Ethics approval and consent to participate

The study and all the participants were reviewed and approved by the laboratory animal center of Nanjing Agricultural University (Nanjing, China). Experimental procedures involving animals and their care were conducted in conformity with Experimental Animal Management Regulations (China's State Council Pub. No.588, Revised 2013). 


\section{Publisher's Note}

Springer Nature remains neutral with regard to jurisdictional claims in published maps and institutional affiliations.

\section{Author details}

'College of Food Science and Technology, Nanjing Agricultural University, Nanjing 210095, China. ${ }^{2}$ College of Food Science and Engineering, Nanjing University of Finance and Economics, Nanjing 210023, China. ${ }^{3}$ Beijing Academy of Food Sciences, Beijing 100068, China.

\section{Received: 30 November 2016 Accepted: 17 May 2017}

\section{Published online: 02 June 2017}

\section{References}

1. Chaudhuri A, Behan PO. Fatigue in neurological disorders. Lancet. 2004;363: 978-88.

2. Mizuno K, Tanaka M, Nozaki S, Mizuma H, Ataka S, Tahara T, et al. Anti-fatigue effects of coenzyme Q10 during physical fatigue. Nutrition. 2008;24:293-9.

3. Schwartz AL. Fatigue mediates the effects of exercise on quality of life. Qual Life Res. 1999:8:529-38.

4. Jung K, Kim I-H, Han D. Effect of medicinal plant extracts on forced swimming capacity in mice. J Ethnopharmacol. 2004;93:75-81.

5. Liu S, Manson JE, Stampfer MJ, Hu FB, Giovannucci E, Colditz GA, et al. A prospective study of whole-grain intake and risk of type 2 diabetes mellitus in us women. Am J Public Health. 2000;90:1409-15.

6. Meyer KA, Kushi LH, Jacobs DR, Slavin J, Sellers TA, Folsom AR. Carbohydrates, dietary fiber, and incident type 2 diabetes in older women. Am J Clin Nutr. 2000;71:921-30.

7. Schatzkin A, Mouw T, Park Y, Subar AF, Kipnis V, Hollenbeck A, et al. Dietary fiber and whole-grain consumption in relation to colorectal cancer in the nih-aarp diet and health study. Am J Clin Nutr. 2007:85:1353-60.

8. Fardet $A$, Rock E, Rémésy C. Is the in vitro antioxidant potential of whole-grain cereals and cereal products well reflected in vivo. J Cereal Sci. 2008:48:258-76.

9. Stark JR, Yin XS. The effect of physical damage on large and small barley starch granules. Starch-Starke. 1986:38:369-74.

10. Ohtsubo Kl, Suzuki K, Yasui Y, Kasumi T. Bio-functional components in the processed pre-germinated brown rice by a twin-screw extruder. J Food Compos Anal. 2005;18:303-16.

11. Altan A, Mccarthy KL, Maskan M. Evaluation of snack foods from barleytomato pomace blends by extrusion processing. J Food Eng. 2008;84:231-42

12. Altan A, McCarthy KL, Maskan M. Effect of screw configuration and raw material on some properties of barley extrudates. J Food Eng. 2009;92:377-82.

13. Company CR. Critical reviews in food science and nutrition. Crit Rev Food Sci. 2009:49:741-81.

14. Gu Y-X, Wang Z-S, Li S-X, Yuan Q-S. Effect of multiple factors on accumulation of nucleosides and bases in cordyceps militaris. Food Chem 2007;102:1304-9.

15. Song CY, Yang BK, Ra KS, Kim HI. Anti-complementary activity of Endopolymers produced from submerged mycelial culture of higher fungi with particular reference to lentinus edodes. Biotechnol Lett. 1998:20:741-4.

16. Mizuno T. Medicinal effects and utilization of cordyceps (fr.) link (ascomycetes) and isaria fr. (mitosporic fungi) Chinese caterpillar fungi, "tochukaso" (review). Int J Med Mushrooms. 1999:1:251-61.

17. Ng TB, Wang HX. Pharmacological actions of cordyceps, a prized folk medicine. J Pharm Pharmacol. 2005:57:1509-19.

18. Huang S-L, Tsi SY, Lee YL, Mau JL. Nonvolatile taste components of fruit bodies and mycelia of cordyceps militaris. Food Chem. 2006:39:577-83.

19. Song J, Wang Y, Teng M, Cai G, Xu H, Guo H, et al. Studies on the antifatigue activities of Cordyceps militaris fruit body extract in mouse model. Evid-Based Compl Al. 2015;2015:1-15.

20. Hamburger M. Comment on comparison of protective effects between cultured cordyceps militaris and natural cordyceps sinensis against oxidative damage. J Agr Food Chem. 2006;54:3132-8.

21. Yue G-G, Lau C-B, Fung K-P, Leung P-C, Ko W-H. Effects of cordyceps sinensis, cordyceps militaris and their isolated compounds on ion transport in calu-3 human airway epithelial cells. J Ethnopharmacology. 2008;117:92-101.

22. Zhang X-L, Ren F, Huang W, Ding R-T, Zhou Q-S, Liu X-L. Anti-fatigue activity of extracts stem bark from acanthopanax senticosus. Molecules. 2011;16:28-37.

23. Ding J-F, Li Y-Y, Xu J-J, Su X-R, Gao X, Yue F-P. Study on effect of jellyfish collagen hydrolysate on anti-fatigue and anti-oxidation. Food Hydrocolloid. 2011;25:1350-53.
24. Glaister M. Mechanisms of fatigue and the influence of aerobic fitness. Sports Med. 2005:35:757-77.

25. Metzger JM, Fitts RH. Role of intracellular pH in muscle fatigue. J Appl Physiol. 1987:62:1392-7.

26. Kim KM, Yu KW, Kang DH, Suh HJ. Anti-stress and anti-fatigue effect of fermented rice bran. Phytother Res. 2002;16:700-2.

27. Qi B, Liu L, Zhang H, Zhou GX, Wang S, Duan XZ, et al. Anti-fatigue effects of proteins isolated from panax quinquefolium. J Ethnopharmacol. 2014; 153:430-4.

28. Uthayathas S, Karuppagounder SS, Tamer SI, Parameshwaran K, Degim T, Suppiramaniam V, et al. Evaluation of neuroprotective and anti-fatigue effects of sildenafil. Life Sci. 2007;81:988-92.

29. Tan W, Yu KQ, Liu YY, Ouyang MZ, Yan MH, Luo R, et al. Anti-fatigue activity of polysaccharides extract from radix rehmanniae preparata. Int J Biol Macromol. 2012:50:59-62.

30. http://www.sdfda.gov.cn/art/2010/2/26/art_206_15132.html. Accessed 26 Feb 2010

31. Lindley AA, Becker S, Gray RH, Herman AA. Effect of continuing or stopping smoking during pregnancy on infant birth weight, crown-heel length, head circumference, ponderal index, and brain:body weight ratio. Am J Epidemiol. 2000;152:219-25.

32. Nielsen FH, Shuler TR. Studies of the interaction between boron and calcium, and its modification by magnesium and potassium, in rats. Biol Trace Elem Res. 1992;35:225-37.

33. Enthoven $L$, de Kloet ER, Oitzl MS. Effects of maternal deprivation of CD1 mice on performance in the water maze and swim stress. Behav Brain Res. 2008;187(1):195

34. Lee JS, Kim HG, Han JM, et al. Anti-fatigue effect of myelophil in a chronic forced exercise mouse model. Eur J Pharmacol. 2015;764:100-8.

35. Zhang H, Liu Y, Zhou J, Wang J, Sun B. Amylopectin is the anti-fatique ingredient in glutinous rice. Int J Biol Macromol. 2014;63:240-3.

36. Wang J, Li S, Fan Y, et al. Anti-fatigue activity of the water-soluble polysaccharides isolated from panax ginseng C. A Meyer J Ethnopharmacol. 2010;130:421-3.

37. Narkhede AN, Jagtap SD, Nirmal PS, Giramkar SA, Nagarkar BE, Kulkarni OP, et al. Anti-fatigue effect of amarkand on endurance exercise capacity in rats. Bmc Complem Altern M. 2016;16:23.

38. Brancaccio P, Maffulli N, Limongelli FM. Creatine kinase monitoring in sport medicine. Br Med Bull. 2007:81:209-30.

39. Ni W-H, Gao T-T, Wang H-L, Du Y-Z, Li J-Y, Li C, et al. Anti-fatigue activity of polysaccharides from the fruits of four Tibetan plateau indigenous medicinal plants. J Ethnopharmacol. 2013;150:529-35.

40. Das SK, Masuda M, Sakurai A, Sakakibara M. Medicinal uses of the mushroom cordyceps militaris: current state and prospects. Fitoterapia. 2010;81:961-8.

41. Wang JJ, Shieh MJ, Kuo SL, Lee CL, Pan TM. Effect of red mold rice on antifatigue and exercise-related changes in lipid peroxidation in endurance exercise. Appl Microbiol Biot. 2006;70:247-53.

42. Ivy JL, Costill DL, Fink WJ, Lower RW. Influence of caffeine and carbohydrate feedings on endurance performance. Med Sci Sport Exer. 1979;11:6-11.

43. Rennie MJ, Winder WW, Holloszy JO. A sparing effect of increased plasma fatty acids on muscle and liver glycogen content in the exercising rat Biochem J. 1976:156:647-55.

44. Wang MY, An LG. Seeds extract on endurance exercise capacity in mice. Med Plants Res. 2011:5:1659-63.

45. You L, Zhao M, Regenstein JM, Ren JY. In vitro antioxidant activity and in vivo anti-fatigue effect of loach (misgurnus anguillicaudatus) peptides prepared by papain digestion. Food Chem. 2011;124:188-94.

46. Aberoumand A, Deokule SS. Proximate and mineral composition of wild coco (eulophia ochreata L.) tubers in Iran. As J Food Ag-Ind. 2009;2:203-9.

47. Hickson RC, Rennie MJ, Conlee RK, Winder WW, Holloszy JO. Effects of increased plasma fatty acids on glycogen utilization and endurance. J Appl Physiol. 1977;43:829-33.

48. Westerblad H, Bruton JD, Katz A. Skeletal muscle: energy metabolism, fiber types, fatigue and adaptability. Exp Cell Res. 2010;316:3093-9.

49. Kim H, Park S, Han DS, Park T. Octacosanol supplementation increases running endurance time and improves biochemical parameters after exhaustion in trained rats. J Med Food. 2003:6:345-50.

50. Wang L, Zhang HL, Lu R, Zhou YJ, Ma R, Lv JQ, et al. The decapeptide CMS001 enhances swimming endurance in mice. Peptides. 2008:29:1176-82.

51. Hsu C-C, Ho M-C, Lin L-C, Su B, Hsu M-C. American ginseng supplementation attenuates creatine kinase level induced by submaximal exercise in human beings. World J of Gastroentero. 2005;11:5327-31. 
52. Jia JM, Wu CF. Anti-fatigue activity of tissue culture extracts of saussurea involucrata. Pharm Biol. 2008;46:433-6.

53. Liu JY, Feng CP, Li X, Chang MC, Meng JL, Xu LL, et al. Immunomodulatory and antioxidative activity of cordyceps militaris polysaccharides in mice. Int J Biol Macromol. 2016;86:594-8.

54. Dong Y, Jing T, Meng Q, Liu C, Hu S, Ma Y, et al. Studies on the antidiabetic activities of cordyceps militaris extract in diet-streptozotocin-induced diabetic sprague-dawley rats. Biomed Res Int. 2014. doi:10.1155/2014/160980.

55. Bafna PA, Balaraman R. Anti-ulcer and antioxidant activity of DHC-1*, a herbal formulation. J Ethnopharmacol. 2004;90:123-7.

56. Chen Y, Miao Y, Huang L, Li J, Sun H, Zhao Y, et al. Anti-oxidant activities of saponins extracted from radix trichosanthis. Bmc Complem Altern M. 2013;14:1-8.

57. Powers S, Lennon SL. Analysis of cellular responses to free radicals: focus on exercise and skeletal muscle. P Nutr Soc. 1999;58:1025-33.

58. Chi A, Li H, Kang C, Guo H, Wang Y, Guo F, et al. Anti-fatigue activity of a novel polysaccharide conjugates from ziyang green tea. Int J Biol Macromol. 2015;80:566-72.

Submit your next manuscript to BioMed Central and we will help you at every step:

- We accept pre-submission inquiries

- Our selector tool helps you to find the most relevant journal

- We provide round the clock customer support

- Convenient online submission

- Thorough peer review

- Inclusion in PubMed and all major indexing services

- Maximum visibility for your research

Submit your manuscript at www.biomedcentral.com/submit 